\title{
Two Tungstates Containing Platinum Nanoparticles Prepared by Air-Calcining Keggin-Type Polyoxotungstate-Coordinated Diplatinum(II) Complexes: Effect on Sintering-Resistance and Photocatalysis
}

\author{
Chika Nozaki Kato $^{1,2}$ (D) $\cdot$ Toshiya Kubota $^{1} \cdot$ Koki Aono $^{1} \cdot$ Naoto Ozawa $^{1}$
}

Received: 14 September 2021 / Accepted: 25 October 2021 / Published online: 5 November 2021

(c) The Author(s) 2021

\begin{abstract}
Two tungstates containing platinum nanoparticles (Pt Npts) were obtained by air-calcining $\alpha$-Keggin-type diplatinum(II)-coordinated polyoxotungstates, $\mathrm{Cs}_{3}\left[\alpha-\mathrm{PW}_{11} \mathrm{O}_{39}\left\{c i s-\mathrm{Pt}\left(\mathrm{NH}_{3}\right)_{2}\right\}_{2}\right] \cdot 8 \mathrm{H}_{2} \mathrm{O}(\mathbf{C s}-\mathrm{P}-\mathrm{Pt})$ and $\mathrm{Cs}_{4}\left[\alpha-\mathrm{SiW}_{11} \mathrm{O}_{39}\left\{c i s-\mathrm{Pt}\left(\mathrm{NH}_{3}\right)_{2}\right\}_{2}\right] \cdot 11 \mathrm{H}_{2} \mathrm{O}$ (Cs-Si-Pt), at $700-900{ }^{\circ} \mathrm{C}$ for $5 \mathrm{~h}$. The polyoxotungstate Cs-P-Pt was transformed to a mixture of Pt Npts and $\mathrm{Cs}_{3} \mathrm{PW}_{12} \mathrm{O}_{40}$ upon calcination, while the Cs-Si-Pt structures were transformed to Pt Npts and $\mathrm{Cs}_{4} \mathrm{~W}_{11} \mathrm{O}_{35}$. The Pt Npts generated by aircalcining Cs-P-Pt at $700{ }^{\circ} \mathrm{C}$ for $5 \mathrm{~h}$ were uniform with an average particle size of $3.6 \pm 1.1 \mathrm{~nm}$, which was much smaller than that of the Pt Npts obtained by calcining Cs-Si-Pt $(19.9 \pm 9.9 \mathrm{~nm})$ under identical conditions. This demonstrated the significant inhibitory effect of Cs-P-Pt on aggregation during high-temperature air-calcination at a high platinum content $\left(10.6\right.$ wt.\%) and in the absence of a support. During calcination at $700-900{ }^{\circ} \mathrm{C}, \mathbf{C s}-\mathbf{P}-\mathbf{P t}$ exhibited higher activities than Cs-Si-Pt with respect to hydrogen evolution from aqueous triethanolamine solutions under visible light irradiation in the presence of Eosin Y, $\alpha$-Keggin-type mono-aluminum-substituted polyoxotungstate, and titanium dioxide. When Cs-P-Pt was calcined at $800^{\circ} \mathrm{C}$ for $100 \mathrm{~h}$, no decrease in activity was observed in comparison with that upon calcination for $5 \mathrm{~h}$.
\end{abstract}

Chika Nozaki Kato

kato.chika@shizuoka.ac.jp

1 Department of Chemistry, Faculty of Science, Shizuoka

University, 836 Ohya, Suruga-ku, Shizuoka 422-8529, Japan

2 Research Institute of Green Science and Technology,

Shizuoka University, 836 Ohya, Suruga-ku,

Shizuoka 422-8529, Japan 


\section{Graphical Abstract}

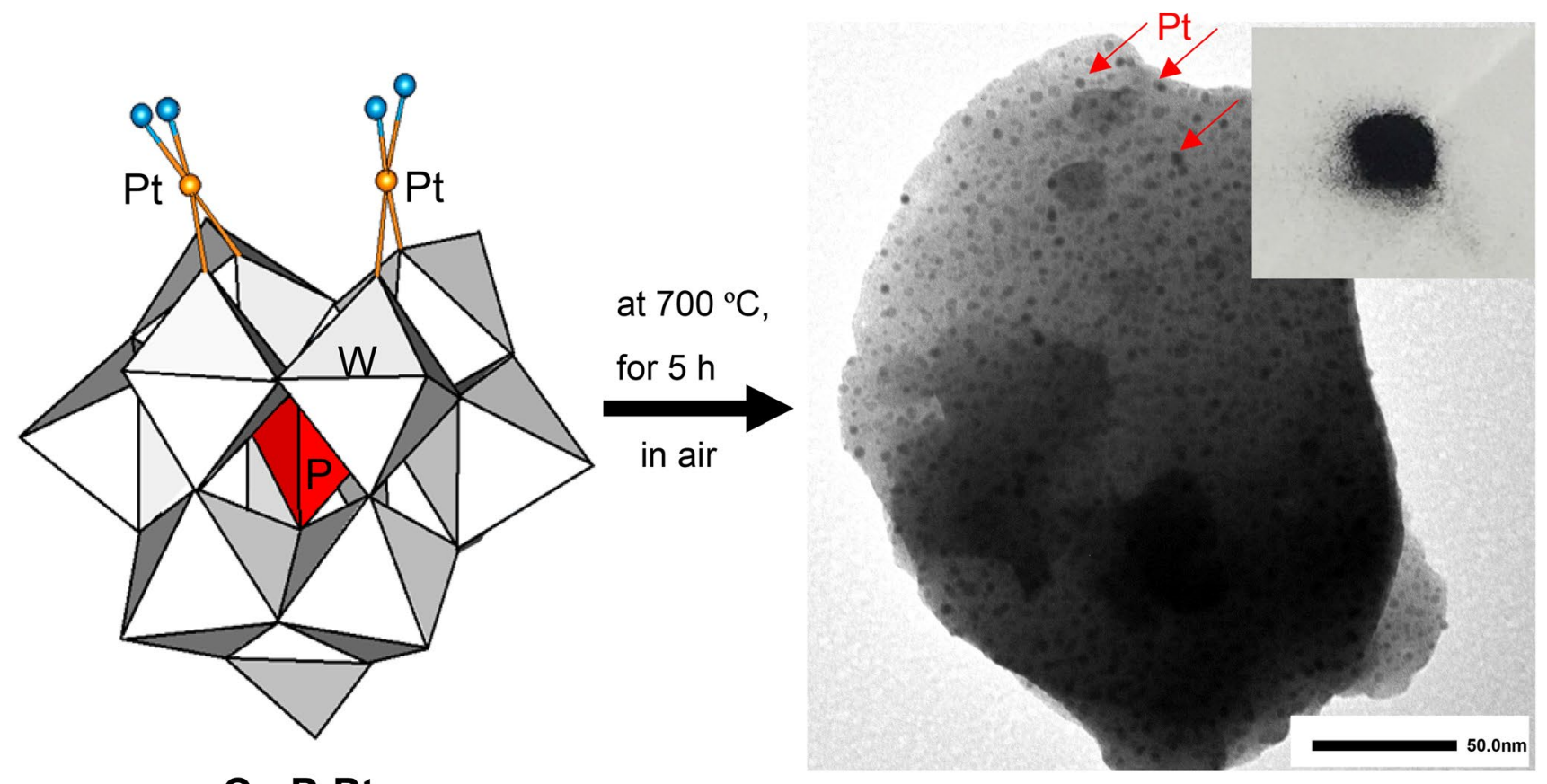

Keywords Polyoxometalate $\cdot$ Platinum nanoparticle $\cdot$ Photocatalysts $\cdot$ Calcination $\cdot$ Hydrogen evolution

\section{Introduction}

Platinum nanoparticle catalysts are extensively used in various industrial processes, including hydrogenation, naphtha reforming, oxidation, automotive exhaust catalysis, and fuel generation (fuel cells) [1, 2]. However, supported platinum nanoparticle catalysts frequently agglomerate into large particles at high reaction temperatures, losing their catalytically active surface areas [3]. For the suppression of such thermally induced deactivation, complex nanostructures, including core-shell nanostructures [4] and well-designed pore structures [5] have been proposed. Although these methods have been successful in maintaining the platinum nanostructures, aggregation still occurs at higher platinum contents and under thermal treatment at higher temperatures.

For the preparation of supported platinum catalysts, various platinum compounds, such as $\mathrm{H}_{2} \mathrm{PtCl}_{6}$, $\mathrm{Pt}\left(\mathrm{NH}_{3}\right)_{4} \mathrm{Cl}_{2}, \mathrm{Pt}\left(\mathrm{NH}_{3}\right)_{4}(\mathrm{OH})_{2}, \mathrm{Pt}\left(\mathrm{NH}_{3}\right)_{4}\left(\mathrm{NO}_{3}\right)_{2}, \mathrm{H}_{2} \mathrm{Pt}(\mathrm{OH})_{6}$, and $\mathrm{Pt}\left(\mathrm{C}_{5} \mathrm{H}_{7} \mathrm{O}_{2}\right)_{2}$ are used as precursors [2]. These compounds are heat-treated in the presence of various gases (air, oxygen, hydrogen, $\mathrm{H}_{2} \mathrm{O}, \mathrm{N}_{2}$, and $\mathrm{Ar}$ ) or under vacuum. In each case, the ligand was eliminated during the heat treatment, and reduction of the oxidized platinum sites $\left(\mathrm{Pt}^{2+}\right.$ and $\left.\mathrm{Pt}^{4+}\right)$ to $\mathrm{Pt}^{0}$ was observed. Further high-temperature treatment induced aggregation.
Lacunary polyoxometalates (POMs) can be used as inorganic ligands to form various types of complexes via coordination of metal ions and organometallics to the vacant site(s) [6-9]. Several structurally well-defined $\mathrm{Pt}^{2+}$-containing $\mathrm{POMs}$, such as $\left[\mathrm{Pt}_{2}\left(\mathrm{~W}_{5} \mathrm{O}_{18}\right)_{2}\right]^{8-}[10],\left[\text { anti- } \mathrm{Pt}_{2}\left(\alpha-\mathrm{PW}_{11} \mathrm{O}_{39}\right)_{2}\right]^{10-}[11]$, and $\left[\text { syn- } \mathrm{Pt}_{2}\left(\alpha-\mathrm{PW}_{11} \mathrm{O}_{39}\right)_{2}\right]^{10-}[11]$ have been reported. Recently, we have synthesized cesium and tetramethylammonium salts of $\alpha$-Keggin and $\alpha_{2}$-Dawson diplatinum(II)-coordinated polyoxotungstates, including $\mathrm{Cs}_{3}\left[\alpha-\mathrm{PW}_{11} \mathrm{O}_{39}\left\{\text { cis }-\mathrm{Pt}\left(\mathrm{NH}_{3}\right)_{2}\right\}_{2}\right] \cdot 8 \mathrm{H}_{2} \mathrm{O}$, $\left[\left(\mathrm{CH}_{3}\right)_{4} \mathrm{~N}\right]_{3}\left[\alpha-\mathrm{PW}_{11} \mathrm{O}_{39}\left\{\text { cis }-\mathrm{Pt}\left(\mathrm{NH}_{3}\right)_{2}\right\}_{2}\right] \cdot 10 \mathrm{H}_{2} \mathrm{O}$, $\left[\left(\mathrm{CH}_{3}\right)_{4} \mathrm{~N}\right]_{4}\left[\alpha-\mathrm{SiW}_{11} \mathrm{O}_{39}\left\{\text { cis- } \mathrm{Pt}\left(\mathrm{NH}_{3}\right)_{2}\right\}_{2}\right] \cdot 13 \mathrm{H}_{2} \mathrm{O}$, $\left[\left(\mathrm{CH}_{3}\right)_{4} \mathrm{~N}\right]_{4}\left[\alpha-\mathrm{GeW}_{11} \mathrm{O}_{39}\left\{\text { cis }-\mathrm{Pt}\left(\mathrm{NH}_{3}\right)_{2}\right\}_{2}\right] \cdot 11 \mathrm{H}_{2} \mathrm{O}$, $\left[\left(\mathrm{CH}_{3}\right)_{4} \mathrm{~N}\right]_{4} \mathrm{H}\left[\alpha-\mathrm{AlW}_{11} \mathrm{O}_{39}\left\{\text { cis- } \mathrm{Pt}\left(\mathrm{NH}_{3}\right)_{2}\right\}_{2}\right] \cdot 11 \mathrm{H}_{2} \mathrm{O}$, $\left[\left(\mathrm{CH}_{3}\right)_{4} \mathrm{~N}\right]_{4} \mathrm{H}\left[\alpha-\mathrm{BW}_{11} \mathrm{O}_{39}\left\{\text { cis }-\mathrm{Pt}\left(\mathrm{NH}_{3}\right)_{2}\right\}_{2}\right] \cdot 9 \mathrm{H}_{2} \mathrm{O}$, $\mathrm{Cs}_{4}\left[\alpha-\mathrm{GeW}_{11} \mathrm{O}_{39}\{\mathrm{Pt}(\mathrm{bpy})\}_{2}\right] \cdot 10 \mathrm{H}_{2} \mathrm{O} \quad$ (bpy $=$ 2,2'-bipyridine), $\mathrm{Cs}_{3.5} \mathrm{H}_{0.5}\left[\alpha-\mathrm{GeW}_{11} \mathrm{O}_{39}\{\mathrm{Pt}(\text { phen })\}_{2}\right] \cdot 3 \mathrm{H}_{2} \mathrm{O}$ $(\mathrm{phen}=1,10-\mathrm{phenanthroline}), \quad$ and $\mathrm{Cs}_{6}\left[\alpha_{2}-\mathrm{P}_{2} \mathrm{~W}_{17} \mathrm{O}_{61}\left\{c i s-\mathrm{Pt}\left(\mathrm{NH}_{3}\right)_{2}\right\}_{2}\right] \cdot 13 \mathrm{H}_{2} \mathrm{O}$ using a similar approach, and demonstrated a long-term steady production of hydrogen with highly effective utilization of the platinum centers for hydrogen production from aqueous ethylenediaminetetraacetic acid disodium salt (EDTA-2Na) and triethanolamine (TEOA) solutions under visible light irradiation [12-16]. 
In the process of improving the activities of the platinum sites, it was found that air calcination of a cesium salt of $\alpha$-Keggin diplatinum(II)-coordinated silicotungstate, $\mathrm{Cs}_{4}\left[\alpha-\mathrm{SiW}_{11} \mathrm{O}_{39}\left\{\text { cis- }-\mathrm{Pt}^{\mathrm{II}}\left(\mathrm{NH}_{3}\right)_{2}\right\}_{2}\right] \cdot 11 \mathrm{H}_{2} \mathrm{O}$, at low temperatures (e.g., $300{ }^{\circ} \mathrm{C}$ ) led to a hydrophilic colloidal species, $\mathrm{Cs}_{4}\left[\left\{\mathrm{Pt}(\mathrm{OH})_{2}\right\}_{2} \cdot \mathrm{SiW}_{12} \mathrm{O}_{40}\right]$ that exhibited excellent photocatalytic activities toward hydrogen evolution from aqueous TEOA solutions under visible-light irradiation [17].

In this paper, we report the formation of two types of tungstates containing Pt Npts, via air-calcination of $\mathrm{Cs}_{3}\left[\alpha-\mathrm{PW}_{11} \mathrm{O}_{39}\left\{\text { cis- } \mathrm{Pt}\left(\mathrm{NH}_{3}\right)_{2}\right\}_{2}\right] \cdot 8 \mathrm{H}_{2} \mathrm{O}$ (Cs-P-Pt) and $\mathrm{Cs}_{4}\left[\alpha-\mathrm{SiW}_{11} \mathrm{O}_{39}\left\{\text { cis- }-\mathrm{Pt}^{\mathrm{II}}\left(\mathrm{NH}_{3}\right)_{2}\right\}_{2}\right] \cdot 11 \mathrm{H}_{2} \mathrm{O}(\mathbf{C s}-\mathrm{Si}-\mathrm{Pt})$ at temperatures ranging from $700{ }^{\circ} \mathrm{C}$ to $900{ }^{\circ} \mathrm{C}$. The -Keggin-type polyoxotungstate unit that remained after calcination had a significant role in suppressing the aggregation of the platinum nanostructures. The calcined samples were characterized using thermogravimetric/differential thermal analysis (TG/DTA), Fourier transform infrared (FT-IR) spectroscopy, X-ray photoelectron spectroscopy (XPS), powder X-ray diffraction (PXRD), and transmission electron microscopy (TEM). The photocatalytic activities of the calcined samples toward hydrogen production from aqueous TEOA solutions were also investigated in the presence of Eosin Y (EY), Keggin-type mono-aluminum-coordinated polyoxometalate, $\mathrm{K}_{5}\left[\alpha-\mathrm{SiW}_{11}\left\{\mathrm{Al}\left(\mathrm{OH}_{2}\right)\right\} \mathrm{O}_{39}\right] \cdot 7 \mathrm{H}_{2} \mathrm{O}$, and titanium dioxide under visible light irradiation $(\lambda \geq 440 \mathrm{~nm})$.

\section{Experimental}

\subsection{Materials and Reagents}

$\mathrm{Cs}_{3}\left[\alpha-\mathrm{PW}_{11} \mathrm{O}_{39}\left\{\text { cis- } \mathrm{Pt}\left(\mathrm{NH}_{3}\right)_{2}\right\}_{2}\right] \cdot 8 \mathrm{H}_{2} \mathrm{O}$ (Cs-P-Pt) [13], $\mathrm{Cs}_{4}\left[\alpha-\mathrm{SiW}_{11} \mathrm{O}_{39}\left\{\text { cis-Pt }\left(\mathrm{NH}_{3}\right)_{2}\right\}_{2}\right] \cdot 11 \mathrm{H}_{2} \mathrm{O}$ (Cs-Si-Pt) [17], $\left[\left(\mathrm{CH}_{3}\right)_{4} \mathrm{~N}\right]_{3}\left[\alpha-\mathrm{PW}_{11} \mathrm{O}_{39}\left\{\text { cis- } \mathrm{Pt}\left(\mathrm{NH}_{3}\right)_{2}\right\}_{2}\right] \cdot 10 \mathrm{H}_{2} \mathrm{O}$ (TMA-PPt) [12], [Pt $\left.\left(\mathrm{NH}_{3}\right)_{4}\right]_{2}\left[\alpha-\mathrm{SiW}_{12} \mathrm{O}_{40}\right] \cdot 4 \mathrm{H}_{2} \mathrm{O}(\mathbf{P t}-\mathrm{SiW12})$ [17], $\mathrm{Na}_{3}\left[\alpha-\mathrm{PW}_{12} \mathrm{O}_{40}\right] \cdot 10 \mathrm{H}_{2} \mathrm{O}[18], \mathrm{K}_{4}\left[\alpha-\mathrm{SiW}_{12} \mathrm{O}_{40}\right] \cdot 17 \mathrm{H}_{2} \mathrm{O}$ [19], $\mathrm{K}_{8}\left[\alpha-\mathrm{SiW}_{11} \mathrm{O}_{39}\right] \cdot 17 \mathrm{H}_{2} \mathrm{O}$ [20], and $\mathrm{Cs}_{4} \mathrm{~W}_{11} \mathrm{O}_{35}$ [21] were prepared via methods described in the literature. The numbers of solvated water molecules were determined through TG/DTA measurements. All reagents and solvents were obtained from commercial sources and used as received. Titanium dioxide (anatase:rutile $=80: 20$ ) and platinum black ( $\leq 20 \mu \mathrm{m} ; \geq 99.95 \%$ purity) were obtained from Wako Pure Chemical Industries, Ltd. and Sigma-Aldrich Co. LLC., respectively.

\subsection{Instrumentation and Analytical Procedures}

The infrared spectra were recorded on a PerkinElmer Spectrum100 FT-IR spectrometer in $\mathrm{KBr}$ discs at approximately $25{ }^{\circ} \mathrm{C}$ in air. The services of Eurofins EAG Materials Science (USA) were enlisted for performing XPS analyses. A monochromated Al $K_{\alpha}$ radiation $(1486.6 \mathrm{eV})$ was used as the $\mathrm{X}$-ray source. The binding energies are referenced to the $\mathrm{C}_{1 s}$ binding energy at $284.8 \mathrm{eV}$. Powder X-ray diffraction (PXRD) measurements were performed on an X-ray powder diffractometer (SmartLab, Rigaku, Corp., Japan) using $\mathrm{Cu} K_{\alpha}$ radiation $(K \alpha=1.54 \AA$ ). Transmission electron microscopy (TEM) images were recorded using a JEOLJEM 2100F electron microscope, and the elemental compositions of the samples were studied using energy-dispersive X-ray spectroscopy (EDS, JED-2300 T (JEOL, Japan)).

\subsection{Photocatalytic Reaction Experiments}

Typical photocatalytic reactions were performed at $25^{\circ} \mathrm{C}$. $\mathrm{EY}$ and $\mathrm{K}_{5}\left[\alpha-\mathrm{SiW}_{11}\left\{\mathrm{Al}\left(\mathrm{OH}_{2}\right)\right\} \mathrm{O}_{39}\right] \cdot 7 \mathrm{H}_{2} \mathrm{O}(2.5 \mu \mathrm{mol})$ were dissolved in $10 \mathrm{~mL}$ of $100 \mathrm{mM}$ aqueous TEOA solution at $\mathrm{pH}$ 7.0. Subsequently, the calcined samples (containing $0.2 \mu \mathrm{mol} \mathrm{Pt}$ ) and titanium dioxide (anatase:rutile $=80: 20$; $50 \mathrm{mg}$ ) were suspended in this solution. The suspension was placed in a glass reaction vessel, which was connected to a Pyrex conventional closed gas circulation system (245.5 $\mathrm{cm}^{3}$ ). The photoreaction was initiated by light irradiation using a $300 \mathrm{~W}$ Xe lamp equipped with a cut-off filter $(\lambda \geq 440 \mathrm{~nm})$. The evolution of hydrogen, oxygen, carbon monoxide, and methane was analyzed using a gas chromatography (GC) instrument equipped with a thermal conductivity detector (TCD), $5 \AA$ molecular sieves, and stainlesssteel columns. The samples were assigned after comparison with standard samples analyzed under identical conditions. The turnover number (TON) was calculated as $2\left[\mathrm{H}_{2}\right.$ evolved $(\mathrm{mol})] /[\mathrm{Pt}$ atoms $(\mathrm{mol})]$.

\section{Results and Discussion}

When Cs-P-Pt was calcined at temperatures from $25^{\circ} \mathrm{C}$ to $800{ }^{\circ} \mathrm{C}$ at a heating rate of $40{ }^{\circ} \mathrm{C} \mathrm{min}-1$, followed by maintaining at $800{ }^{\circ} \mathrm{C}$ for $5 \mathrm{~h}$ in air (without flow), its color changed from yellow to black (the calcined sample was denoted as Cs-P-Pt-800-5), and the obtained powder was insoluble in water.

The FT-IR spectrum of Cs-P-Pt-800-5 contains several bands at $1079 \mathrm{~cm}^{-1}, 985 \mathrm{~cm}^{-1}, 888 \mathrm{~cm}^{-1}$, and $804 \mathrm{~cm}^{-1}$, as shown in Fig. 1a. These bands are remarkably different from those of as-prepared Cs-P-Pt $\left(1099 \mathrm{~cm}^{-1}, 1047 \mathrm{~cm}^{-1}\right.$, $955 \mathrm{~cm}^{-1}, 915 \mathrm{~cm}^{-1}, 859 \mathrm{~cm}^{-1}, 801 \mathrm{~cm}^{-1}, 757 \mathrm{~cm}^{-1}$, and $721 \mathrm{~cm}^{-1}$ ) (Fig. 1b) [13] but almost identical to those of $\mathrm{Na}_{3}\left[\alpha-\mathrm{PW}_{12} \mathrm{O}_{40}\right] \cdot 12 \mathrm{H}_{2} \mathrm{O}\left(1080 \mathrm{~cm}^{-1}, 984 \mathrm{~cm}^{-1}, 893 \mathrm{~cm}^{-1}\right.$, and $\left.808 \mathrm{~cm}^{-1}\right)$ [18] and $\mathrm{Cs}_{3}\left[\alpha-\mathrm{PW}_{12} \mathrm{O}_{40}\right]\left(1080 \mathrm{~cm}^{-1}\right.$, $890 \mathrm{~cm}^{-1}$, and $798 \mathrm{~cm}^{-1}$ ) [22], suggesting that the structure of the $\alpha$-Keggin-type mono-lacunary polyoxotungstate ligand, $\left\{\mathrm{PW}_{11} \mathrm{O}_{39}\right\}$, in Cs-P-Pt transformed to $\left\{\mathrm{PW}_{12} \mathrm{O}_{40}\right\}$ under the applied thermal treatment conditions. The band 

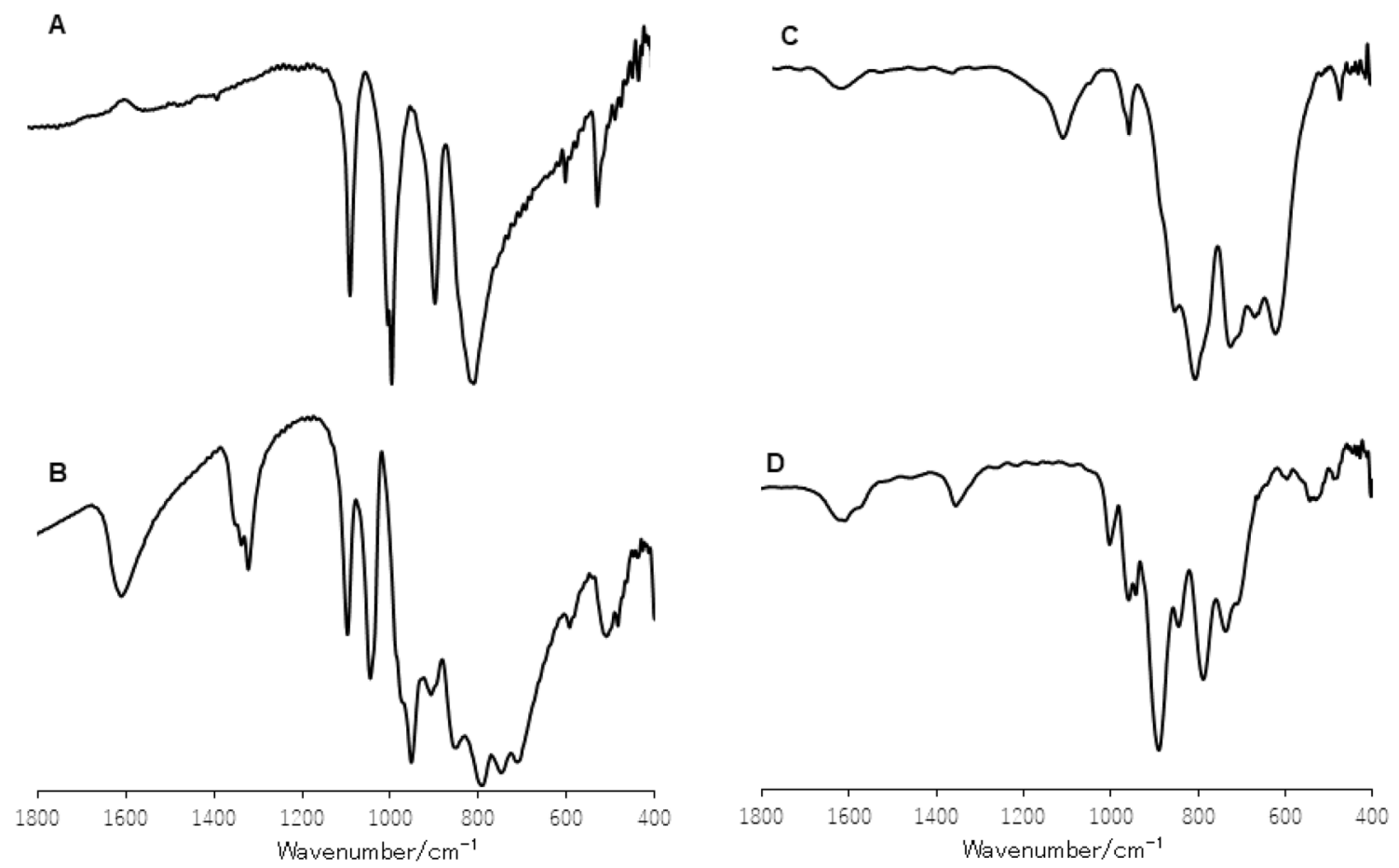

Fig. 1 FT-IR spectra of a Cs-P-Pt-800-5, b Cs-P-Pt, c Cs-Si-Pt-800-5, and d Cs-Si-Pt

at $1356 \mathrm{~cm}^{-1}$ corresponding to the four $\mathrm{NH}_{3}$ groups disappeared, indicating the complete removal of the four ammonia molecules. The same bands as Cs-P-Pt-800-5 were observed for the samples obtained by calcination at $700{ }^{\circ} \mathrm{C}$ and $900{ }^{\circ} \mathrm{C}$ (these samples are denoted as Cs-P-Pt-700-5 and Cs-P-Pt-900-5, respectively), as shown in Fig. S1. This proved that the $\alpha$-Keggin structure was maintained at least up to $900{ }^{\circ} \mathrm{C}$.

When Cs-Si-Pt was calcined at $800{ }^{\circ} \mathrm{C}$ for $5 \mathrm{~h}$ (the calcined sample is denoted as Cs-Si-Pt-800-5), its color changed from yellow to gray, and the obtained powder was insoluble in water. The FT-IR spectrum (Fig. 1c) of Cs-SiPt-800-5 showed bands at $968 \mathrm{~cm}^{-1}, 889 \mathrm{~cm}^{-1}, 861 \mathrm{~cm}^{-1}$, $812 \mathrm{~cm}^{-1}, 779 \mathrm{~cm}^{-1}, 730 \mathrm{~cm}^{-1}, 717 \mathrm{~cm}^{-1}$, and $672 \mathrm{~cm}^{-1}$, which were different from those observed for the as-prepared Cs-Si-Pt $\left(1004 \mathrm{~cm}^{-1}, 960 \mathrm{~cm}^{-1}, 944 \mathrm{~cm}^{-1}, 891 \mathrm{~cm}^{-1}\right.$, $846 \mathrm{~cm}^{-1}, 789 \mathrm{~cm}^{-1}, 738 \mathrm{~cm}^{-1}$, and $712 \mathrm{~cm}^{-1}$ ) (Fig. 1d) but similar to those of $\mathrm{Cs}_{4} \mathrm{~W}_{11} \mathrm{O}_{35}\left(969 \mathrm{~cm}^{-1}, 860 \mathrm{~cm}^{-1}\right.$, $816 \mathrm{~cm}^{-1}, 780 \mathrm{~cm}^{-1}, 707 \mathrm{~cm}^{-1}$, and $675 \mathrm{~cm}^{-1}$ ), which was obtained via a method described in the literature [21]. The same spectral pattern (Fig. S2) was observed when Cs-Si$\mathbf{P t}$ was calcined at $700{ }^{\circ} \mathrm{C}$ and $900{ }^{\circ} \mathrm{C}$ (the calcined samples are denoted as Cs-Si-Pt-700-5 and Cs-Si-Pt-900-5). The four $\mathrm{NH}_{3}$ groups coordinated to the di-platinum site in CsSi-Pt were vaporized, as previously reported [17]. A band appeared at $1123 \mathrm{~cm}^{-1}$ which was attributed to the $\mathrm{Si}-\mathrm{O}-\mathrm{Si}$ stretching, suggesting that the internal $\left\{\mathrm{SiO}_{4}\right\}$ unit in the Keggin structure was transformed to silicon oxide [23].
The PXRD pattern of Cs-P-Pt-800-5 (Fig. 2a) showed the same peaks as that of $\mathrm{Cs}_{3} \mathrm{PW}_{12} \mathrm{O}_{40}$ (ICDD: 00-050-1857), and similar peaks were observed for Cs-P-Pt-700-5 and CsP-Pt-900-5, as shown in Fig. S3. These results prove that the $\left\{\mathrm{PW}_{11} \mathrm{O}_{39}\right\}$ unit in $\mathbf{C s}-\mathbf{P}-\mathbf{P t}$ was transformed to $\left\{\mathrm{PW}_{12} \mathrm{O}_{40}\right\}$ under the reported thermal treatment conditions. This was validated by the FT-IR spectra. In contrast, the PXRD pattern of Cs-Si-Pt-800-5 (Fig. 2b) exhibited the same peaks as that of $\mathrm{Cs}_{4} \mathrm{~W}_{11} \mathrm{O}_{35}$ (ICDD: 00-051-1891). A similar structural transformation of the $\left\{\mathrm{SiW}_{11} \mathrm{O}_{39}\right\}$ unit to $\left\{\mathrm{W}_{11} \mathrm{O}_{35}\right\}$ was observed for Cs-Si-Pt-700-5 and Cs-Si-Pt-900-5, as shown in Fig. S4. As previously reported, the $\left\{\mathrm{SiW}_{11} \mathrm{O}_{39}\right\}$ unit in Cs-Si-Pt was transformed to $\left\{\mathrm{SiW}_{12} \mathrm{O}_{40}\right\}$ by air calcination in the lower temperature range of $250-500{ }^{\circ} \mathrm{C}$ [17]. However, at higher temperatures in the range of $700{ }^{\circ} \mathrm{C}$ to $900{ }^{\circ} \mathrm{C}$, the Keggin structure was transformed to $\left\{\mathrm{W}_{11} \mathrm{O}_{35}\right\}$.

A broad peak corresponding to $\operatorname{Pt}(111)\left(2 \theta\left(^{\circ}\right)=40\right.$, ICDD: 00-04-0802) was observed. This indicates that the di-platinum(II) sites in Cs-P-Pt and Cs-Si-Pt were reduced to crystalline $\operatorname{Pt}(0)$ by the applied thermal treatment. As shown in Figs. 2, S3 and S4, the peak intensity increased as the calcination temperature was increased. These results suggest that the crystallite size of platinum increases with the calcination temperature.

The Pt(4f) XPS spectra of Cs-P-Pt-800-5 and Cs-SiPt-800-5 are shown in Fig. 3. In both the spectra, the platinum sites were primarily composed of $\mathrm{Pt}^{0}$, with low levels of $\mathrm{Pt}^{2+}$ and $\mathrm{Pt}^{4+}$. The occurrence of $\mathrm{Pt}^{4+}$ needs to be 
Fig. 2 Powder XRD patterns of a Cs-P-Pt-800-5 and b Cs-Si-Pt-800-5. The peaks of $\mathrm{Cs}_{3} \mathrm{PW}_{12} \mathrm{O}_{40}, \mathrm{Cs}_{4} \mathrm{~W}_{11} \mathrm{O}_{35}$, and $\mathrm{Pt}(111)$ are marked with white and black rhombuses, and a red arrow, respectively
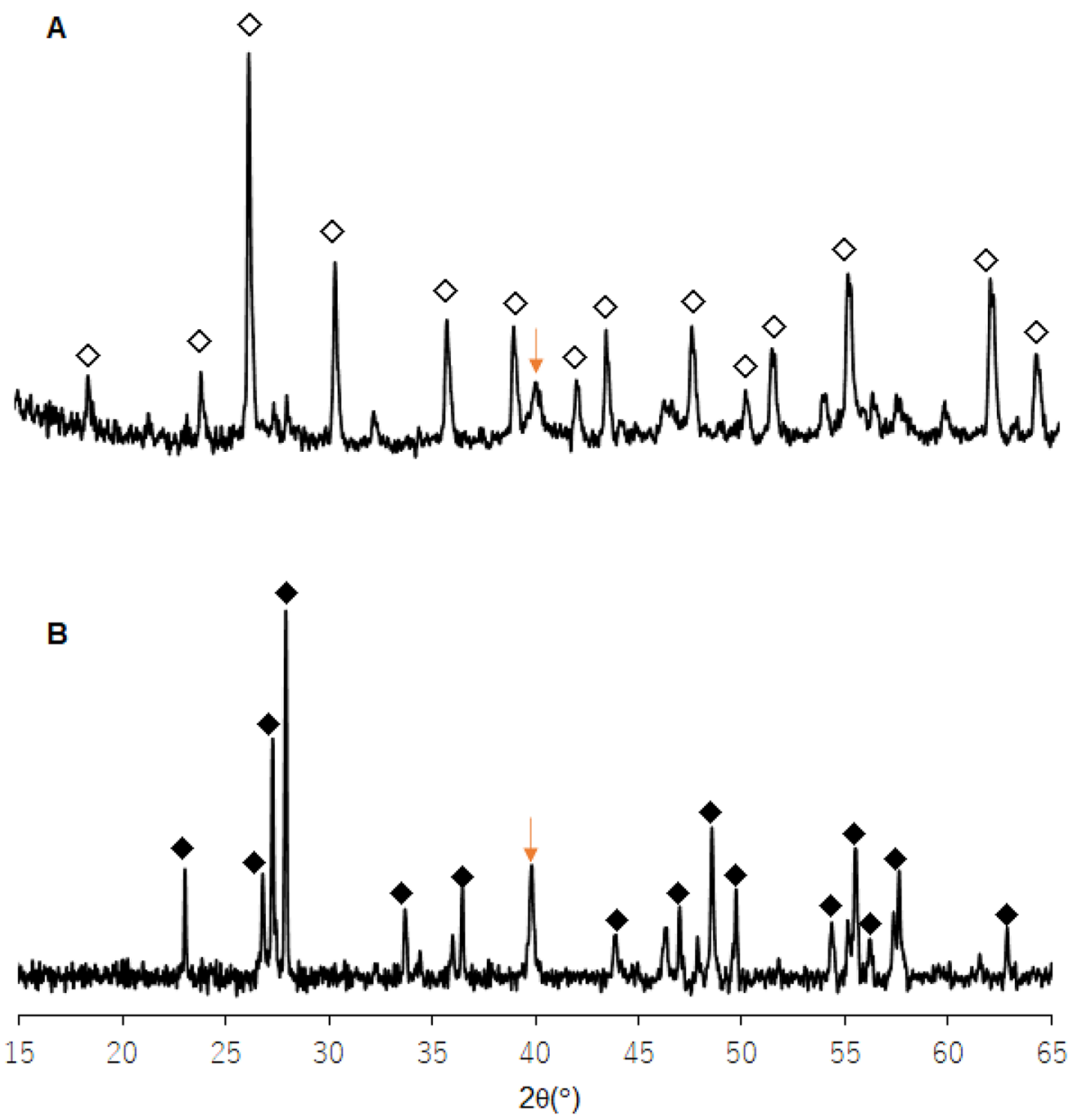

interpreted with caution because of the high levels of signal overlap with Cs(4d). The W(4f) XPS spectra (Figs. S5a and S6a) of Cs-P-Pt-800-5 and Cs-Si-Pt-800-5 showed that the tungsten sites were composed of $\mathrm{W}^{6+}$. The $\mathrm{Cs}(3 \mathrm{~d})$ XPS spectra of Cs-P-Pt-800-5 and Cs-Si-Pt-800-5 indicated that the existence of cesium in the monovalent form, as shown in Figs. S5b and S6b.

Figure $4 \mathrm{a}$ and $\mathrm{b}$ show TEM images of Cs-P-Pt-700-5 and -800-5. The corresponding size distributions are shown in Figs. 4c and 4d. Homogeneously dispersed $\mathrm{Pt}$ Npts can be observed as small black grains in the tungstate matrix. The average sizes of the Pt Npts in the calcined samples are summarized in Table 1. Surprisingly, Cs-PPt-700-5 and Cs-P-Pt-800-5 exhibited average particle sizes of $3.6 \pm 1.1 \mathrm{~mm}$ and $5.3 \pm 2 \mathrm{~nm}$, respectively, at a high platinum content (10.6 wt.\%), in the absence of a support. The average particle size of Cs-P-Pt-900-5 was $9.3 \pm 2.8 \mathrm{~nm}$, which was approximately twice that of CsP-Pt-800-5, indicating slight aggregation at $900{ }^{\circ} \mathrm{C}(\mathrm{Fig}$. $\mathrm{S} 7)$. However, the average particle size reached upon calcination at $800{ }^{\circ} \mathrm{C}$ for $100 \mathrm{~h}$ was $5.4 \pm 1.9 \mathrm{~nm}$, and negligible aggregation of Pt Npts was observed after long-term heat treatment, as shown in Fig. S8.
In contrast, the average sizes of the Pt Npts in CsSi-Pt-700-5, -800-5, and -900-5 were $19.9 \pm 9.9 \mathrm{~mm}$, $42.8 \pm 21.2 \mathrm{~mm}$, and $100.8 \pm 70.7 \mathrm{~nm}$, respectively, and the particle sizes increased remarkably with the calcination temperature, as shown in Figs. 5, S9a, and S10. The black grains were confirmed to be platinum particles via tungsten and platinum EDS mapping (Figs. S9b and 9c).

As a control experiment, $\mathrm{Pt}$ Npt-supported $\mathrm{TiO}_{2}$ (Pt content: $11 \mathrm{wt} \%$ ) was prepared as follows: cisdiamminedichloroplatinum(II) (cisplatin) (0.169 g; $0.56 \mathrm{mmol})$ was dissolved in $50 \mathrm{~mL}$ water. $\mathrm{TiO}_{2}(0.83 \mathrm{~g})$ was added to the solution, and the mixture was stirred for $2 \mathrm{~h}$ at approximately $25^{\circ} \mathrm{C}$. After evaporation to dryness at $100{ }^{\circ} \mathrm{C}$, the obtained solid was calcined at $700{ }^{\circ} \mathrm{C}$ for $5 \mathrm{~h}$ in air. The calcined product was denoted as cisplatin/ $\mathbf{T i O} \mathbf{2}_{-}$ 700-5. The average particle size of cisplatin/ $\mathrm{TiO}_{\mathbf{2}} \mathbf{- 7 0 0 - 5}$ was $31.4 \pm 19.7 \mathrm{~nm}$, which was larger than that of Cs-PPt-700-5 and Cs-Si-Pt-700-5, as shown in Fig. S11. When the platinum salt of $\alpha$-Keggin silicotungstate $\left[\mathrm{Pt}\left(\mathrm{NH}_{3}\right)_{4}\right]_{2}[\alpha-$ $\left.\mathrm{SiW}_{12} \mathrm{O}_{40}\right] \cdot 4 \mathrm{H}_{2} \mathrm{O}$ (platinum content: $11.2 \mathrm{wt} . \%$ ) was calcined at $800{ }^{\circ} \mathrm{C}$ for $5 \mathrm{~h}$ in air (the calcined product was denoted as Pt-SiW12-800-5), particles with non-uniform sizes were formed with some particles growing above $50 \mathrm{~nm}$ 

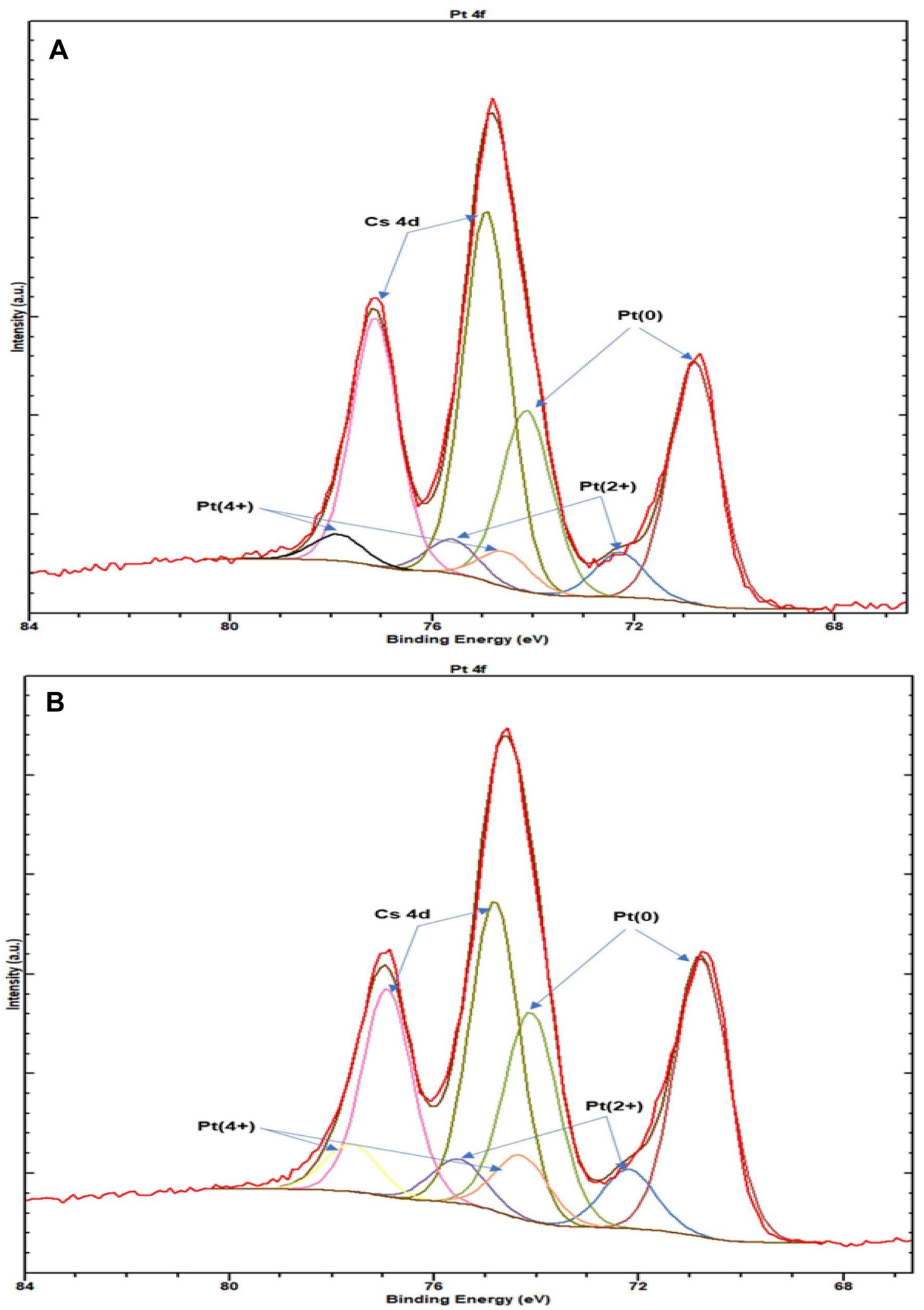

Fig. $3 \mathrm{Pt}(4 \mathrm{f})$ XPS spectra in the range 66.5-84 eV of a Cs-P-Pt-800-5 and b Cs-Si-Pt-800-5 

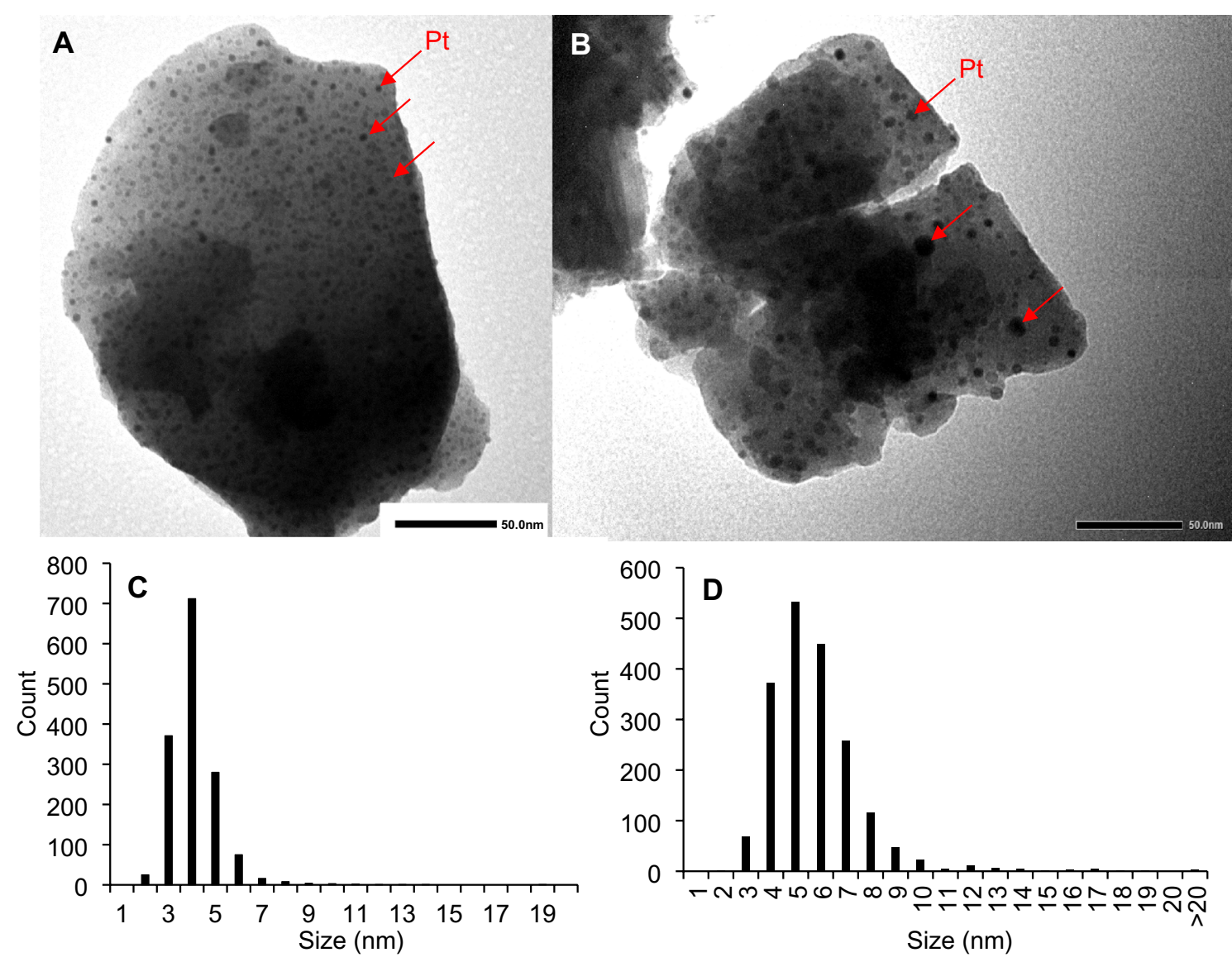

Fig. 4 TEM images of a Cs-P-Pt-700-5 and b Cs-P-Pt-800-5. The Pt particle size distributions of Pt Npts in Cs-P-Pt-700-5 and Cs-P-Pt-800-5 are shown in $\mathbf{c}$ and $\mathbf{d}$, respectively

Table 1 Average size of Pt Npts in the calcined samples

\begin{tabular}{lcc}
\hline calcined sample & Pt content (wt.\%) & $\begin{array}{l}\text { average Pt } \\
\text { Npts size } \\
(\mathrm{nm})\end{array}$ \\
\hline Cs-P-Pt-700-5 & $10.6^{\mathrm{a}}$ & $3.6 \pm 1.1$ \\
Cs-P-Pt-800-5 & & $5.3 \pm 2$ \\
Cs-P-Pt-900-5 & & $9.3 \pm 2.8$ \\
Cs-P-Pt-800-100 & & $5.4 \pm 1.9$ \\
Cs-Si-Pt-700-5 & $10.1^{\mathrm{a}}$ & $19.9 \pm 9.9$ \\
Cs-Si-Pt-800-5 & & $42.8 \pm 21.2$ \\
Cs-Si-Pt-900-5 & & $100.8 \pm 70.7$ \\
cisplatin/TiO $-\mathbf{- 7 0 0 - 5}$ & 11.0 & $31.4 \pm 19.7$ \\
\hline
\end{tabular}

${ }^{\mathrm{a}}$ The platinum contents were calculated based on the composition formulae of Cs-P-Pt and Cs-Si-Pt

(Fig. S12a). It can be seen from the FT-IR spectrum of PtSiW12-800-5 (Fig. S12b) that the Keggin-type structure was decomposed and $\left\{\mathrm{W}_{11} \mathrm{O}_{35}\right\}$ unit was not formed. A platinum salt of phosphotungstate retaining the structure of $\mathrm{PW}_{12} \mathrm{O}_{40}{ }^{3-}$ could not be obtained using the same method as that used to obtain $\mathrm{SiW}_{12} \mathrm{O}_{40}{ }^{4-}$. It was confirmed from the FT-IR spectrum (Fig. S13b) that the Keggin structure was decomposed when TMA-P-Pt (platinum content: 11 wt.\%) was calcined at $800{ }^{\circ} \mathrm{C}$ for $5 \mathrm{~h}$ in air (the obtained sample was denoted as TMA-P-Pt-800-5). The particle size was non-uniform, and some particles grew to several tens of nanometers, as shown in Fig. S13a.

According to these results, Cs-P-Pt, which retained the $\alpha$-Keggin polyoxotungstate and $\mathrm{Cs}_{3} \mathrm{PW}_{12} \mathrm{O}_{40}$ after calcination, exhibited an excellent aggregation inhibitory effect at high platinum content and in the absence of a support. Such inhibition of platinum aggregation is not observed in platinum compounds from which the ligands disappear upon calcination [2]. It is critical to coordinate the platinum species to the mono-vacant sites in $\alpha$-Keggin-type mono-lacunary phosphotungstates and isolate them as cesium salts for the expression of such an effect.

The activities of the Pt Npts in the calcined samples as co-catalysts were studied by using Cs-P-Pt-800-5 and Cs-SiPt-800-5 to catalyze the evolution of hydrogen from aqueous TEOA solutions under light irradiation $(\lambda \geq 440 \mathrm{~nm})$ in the presence of Eosin Y (EY), $\mathrm{K}_{5}\left[\alpha-\mathrm{SiW}_{11}\left\{\mathrm{Al}\left(\mathrm{OH}_{2}\right)\right\}\right.$ $\left.\mathrm{O}_{39}\right] \cdot 7 \mathrm{H}_{2} \mathrm{O}$ (denoted as $\mathbf{K}-\mathbf{S i}-\mathbf{A l}$ ), and titanium dioxide 


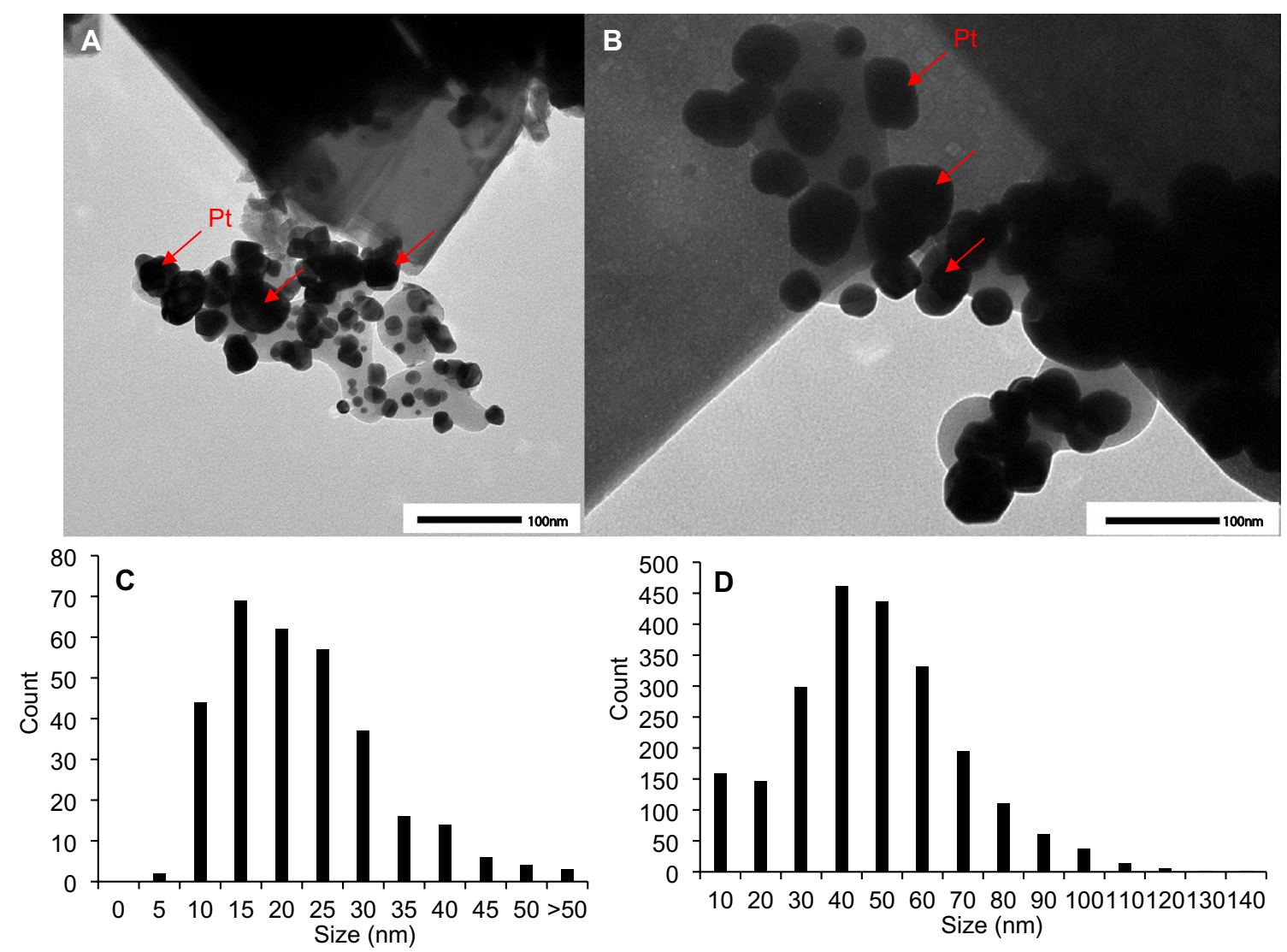

Fig. 5 TEM images of a Cs-Si-Pt-700-5 and b Cs-Si-Pt-800-5. The Pt particle size distributions in Cs-Si-Pt-700-5 and Cs-Si-Pt-800-5 are shown in $\mathbf{c}$ and $\mathbf{d}$, respectively

(anatase:rutile $=80: 20$ ), as shown in Figs. 6a and b [14, 17, 24, 25]. The precursors, Cs-P-Pt and Cs-Si-Pt were weighted while ensuring that the amount of platinum was $0.2 \mu \mathrm{mol}$ (the contents of $\mathrm{Pt}$ in the catalysts containing $\mathrm{TiO}_{2}$ and the platinum samples were $0.084 \mathrm{wt} . \%$ and $0.080 \mathrm{wt} . \%$, respectively). Subsequently, they were calcined at $800{ }^{\circ} \mathrm{C}$ for $5 \mathrm{~h}$ in air. TEOA was used as the sacrificial reagent. EY and K-Si-Al were used as the photosensitizer and EY stabilizer, respectively. Although $\mathrm{TiO}_{2}$ was used to promote charge separation, the tungstates containing Pt Npts were not supported on the surface of $\mathrm{TiO}_{2}$. In order to compare the activities with the samples before calcination, $\mathrm{TiO}_{2}$ was simply dispersed in the solutions. Hydrogen was formed with $100 \%$ selectivity, and oxygen, carbon dioxide, carbon monoxide, and methane were not detected under these reaction conditions. It has already been confirmed that no reaction was observed in the absence of platinum catalysts or Eosin $\mathrm{Y}$ under the reported conditions.

After $6 \mathrm{~h}$ of light irradiation, the amounts of hydrogen evolved in presence of Cs-P-Pt-800-5 and Cs-Si-Pt-800-5 were $180 \mu \mathrm{mol}$ and $156 \mu \mathrm{mol}$, respectively, The TONs $(=2[$ hydrogen evolved $(\mathrm{mol})] /[\mathrm{Pt}$ atoms $(\mathrm{mol})])$ observed for Cs-P-Pt-800-5 and Cs-Si-Pt-800-5 were 1801 and
1556, respectively. These values were higher than those of Cs-P-Pt and Cs-Si-Pt (TONs observed after $6 \mathrm{~h}$ were 703 and 409, respectively. These results suggest that the photocatalytic activities of Cs-P-Pt and Cs-Si-Pt were improved upon calcination. The turnover frequencies $(\mathrm{TOF}=\mathrm{TON} /$ reaction time (h)) of Cs-P-Pt-800-5 and Cs-Si-Pt-800-5 after $1 \mathrm{~h}$ were 685 and $336 \mathrm{~h}^{-1}$, respectively. These values are higher than those of similar photocatalytic systems containing platinum co-catalysts prepared via the photoreduction of $\mathrm{H}_{2} \mathrm{PtCl}_{6}, \mathrm{EY}$, and $\mathrm{TiO}_{2}$. For example, the TOFs of $\mathrm{Pt} / \mathrm{EY} /$ nitrogen-doped $\mathrm{TiO}_{2}$ [26], $\mathrm{Pt} / \mathrm{EY} /$ modified $\mathrm{TiO}_{2}$ with phosphate [27], $\mathrm{Pt} / \mathrm{EY} / \mathrm{Fe}^{3+} / \mathrm{TiO}_{2}$ [28], and $\mathrm{Pt} / \mathrm{EY} /$ $\mathrm{SiW}_{11} \mathrm{O}_{39}{ }^{8-} / \mathrm{TiO}_{2}$ [25] are less than $150 \mathrm{~h}^{-1}$ with respect to hydrogen evolution from aqueous TEOA solutions under visible-light irradiation. When platinum black $(3.0 \mu \mathrm{mol} \mathrm{Pt})$ was used as a co-catalyst, the TOF after $1 \mathrm{~h}$ was $11.7 \mathrm{~h}^{-1}$, which was significantly lower than those of Cs-P-Pt-800-5 and Cs-Si-Pt-800-5. It is difficult to discuss the differences in activities based on the sizes of the $\mathrm{Pt} \mathrm{Npts}$ alone because of the influences of $\mathrm{Cs}_{3} \mathrm{PW}_{12} \mathrm{O}_{40}$ and $\mathrm{Cs}_{4} \mathrm{~W}_{11} \mathrm{O}_{35}$ contained in Cs-P-Pt-800-5 and Cs-Si-Pt-800-5, respectively. However, upon calcination at $700-900{ }^{\circ} \mathrm{C}$, Cs-P-Pt showed higher activities than Cs-Si-Pt, as shown in Fig. 7. Upon 

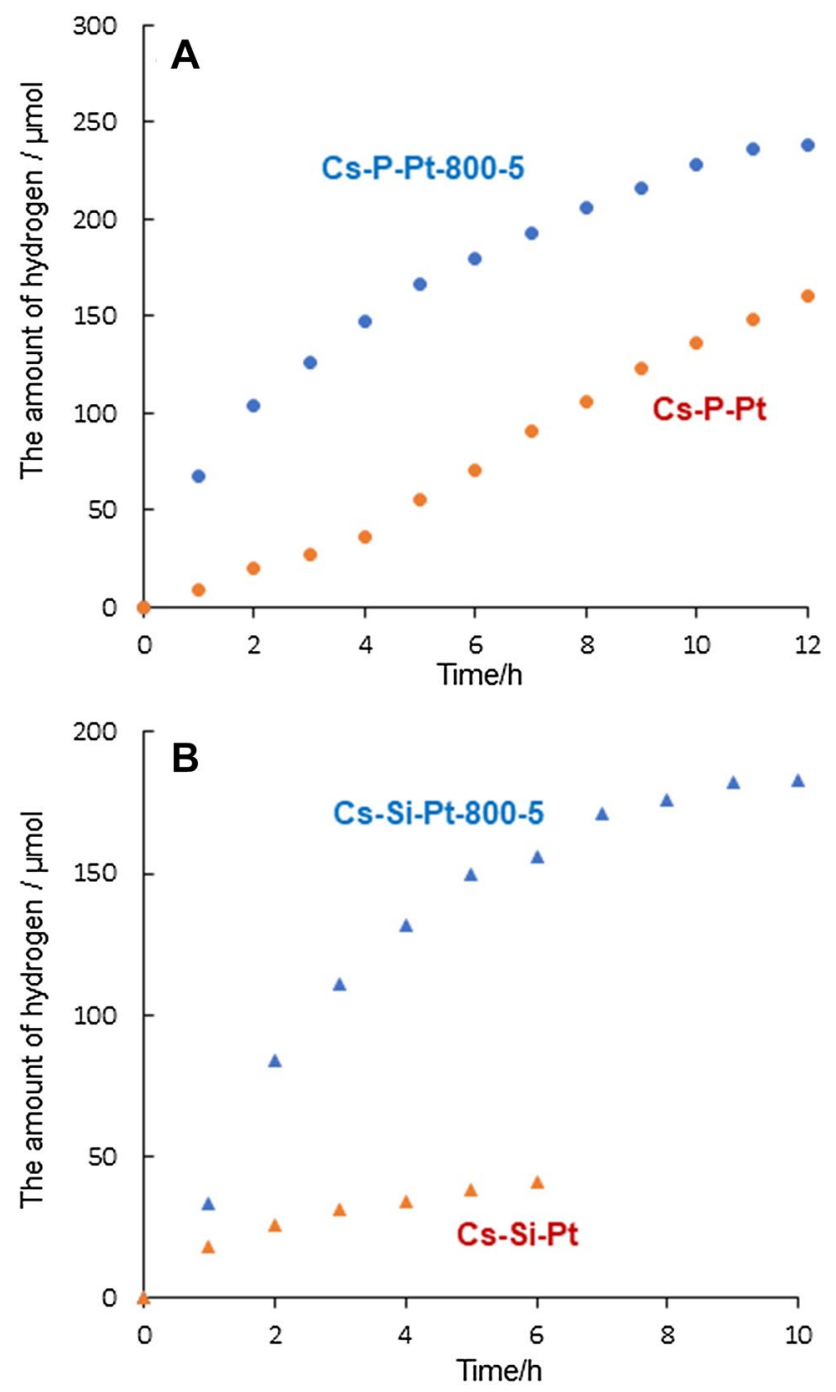

Fig. 6 Time course for hydrogen evolution catalyzed by a Cs-PPt-800-5 and Cs-P-Pt, and b Cs-Si-Pt-800-5 and Cs-Si-Pt. Reaction conditions: platinum catalyst $(0.2 \mu \mathrm{mol} \mathrm{Pt}), \mathrm{EY}(2.5 \mu \mathrm{mol}), \mathbf{K}-\mathbf{S i}-\mathbf{A l}$ $(2.5 \mu \mathrm{mol}), \mathrm{TiO}_{2}$ (anatase:rutile $\left.=80: 20\right) 50 \mathrm{mg}, 100 \mathrm{mM}$ aqueous TEOA solution $(10 \mathrm{~mL}, \mathrm{pH} 7)$, light irradiation $(\lambda \geq 440 \mathrm{~nm}), 25^{\circ} \mathrm{C}$

using Cs-P-Pt-800-100, $192 \mu \mathrm{mol}$ hydrogen was generated after $6 \mathrm{~h}$ (TON: 1919), and there was no reduction in catalytic activity upon extending the calcination time from $5 \mathrm{~h}$ to $100 \mathrm{~h}$.

In the cases of Cs-P-Pt-800-5 and Cs-Si-Pt-800-5, the amount of hydrogen generated gradually decreased with time, as shown in Figs. 6a and b. For the hydrophilic platinum-polyoxotungstate colloidal particles obtained by air-calcining Cs-Si-Pt at $300{ }^{\circ} \mathrm{C}$ for $5 \mathrm{~h}$, the TON after $3 \mathrm{~h}$ exceeded 4600 under similar reaction conditions. However, rapid decomposition of the platinum sites was observed and the activity did not improve upon re-addition of EY [17]. To confirm that Cs-P-Pt-800-5 was not decomposed, we performed the following experiment: The

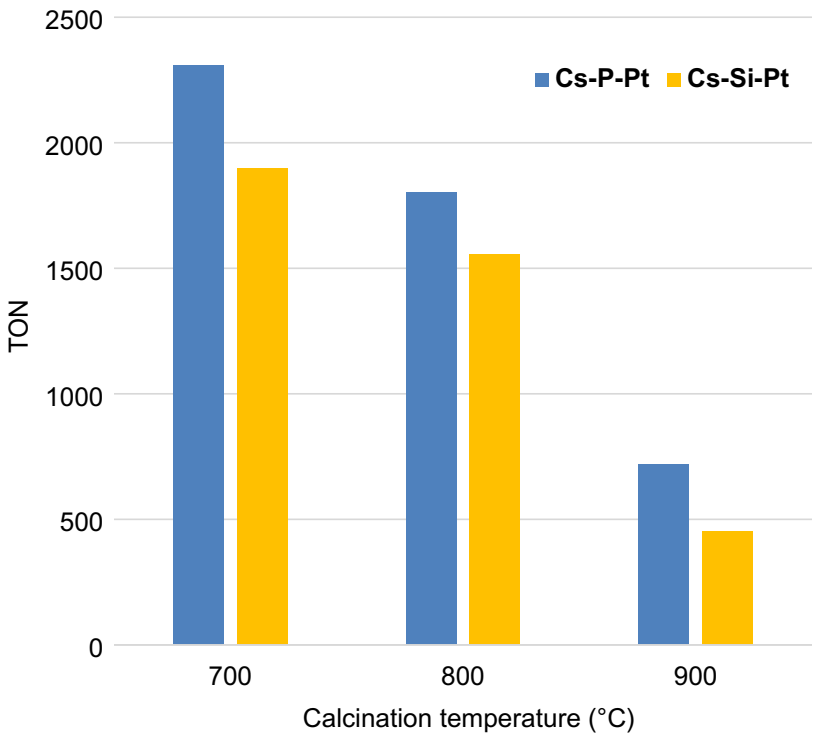

Fig. 7 A plot of TON after $6 \mathrm{~h}$ vs. calcination temperature of Cs-P-Pt and Cs-Si-Pt for hydrogen evolution from aqueous TEOA under visible light irradiation. Reaction conditions are shown in the caption of Fig. 6

aforementioned photocatalytic reaction was performed in the presence of Cs-P-Pt-800-5 $(0.2 \mu \mathrm{mol} \mathrm{Pt})$ under light irradiation for $20 \mathrm{~h}$. The residual solid was collected using a membrane filter (JG $0.2 \mu \mathrm{m})$ and washed with water and ethanol. Thereafter, the solid containing Cs-P-Pt-800-5 and $\mathrm{TiO}_{2}$ was dispersed again in an aqueous TEOA solution containing EY and K-Si-Al. After $6 \mathrm{~h}$ of light irradiation, approximately $200 \mu \mathrm{mol}$ of hydrogen was generated. It was also confirmed that the photocatalytic activity of Cs-Si-Pt-800-5 was restored by the re-addition of EY (Fig. S14). These results demonstrate that Cs-P-Pt-800-5 and Cs-Si-Pt-800-5 did not decompose under the applied reaction conditions and were recyclable.

Finally, the following experiment was conducted to investigate the sizes of the Pt Npts after light irradiation: Cs-P-Pt-800-5 (37.6 mg) was dispersed in aqueous TEOA containing dissolved EY, and subjected to light irradiation for $6 \mathrm{~h}$. The residual solid was collected through a membrane filter (JG $0.2 \mu \mathrm{m}$ ) and washed with water and ethanol. The TEM images and the corresponding size distributions of the obtained samples are shown in Figs. 8a and b. After light irradiation, homogeneously dispersed Pt Npts were observed in the tungstate matrix. The average particle size was $5.1 \pm 2.5 \mathrm{~nm}$, which was nearly the same as that prior to light irradiation. Although it has been reported that the sizes of Pt Npts increase during hydrogen evolution under light irradiation [29], no aggregation of the Pt Npts comprising Cs-P-Pt-800-5 was observed under the applied reaction conditions. 


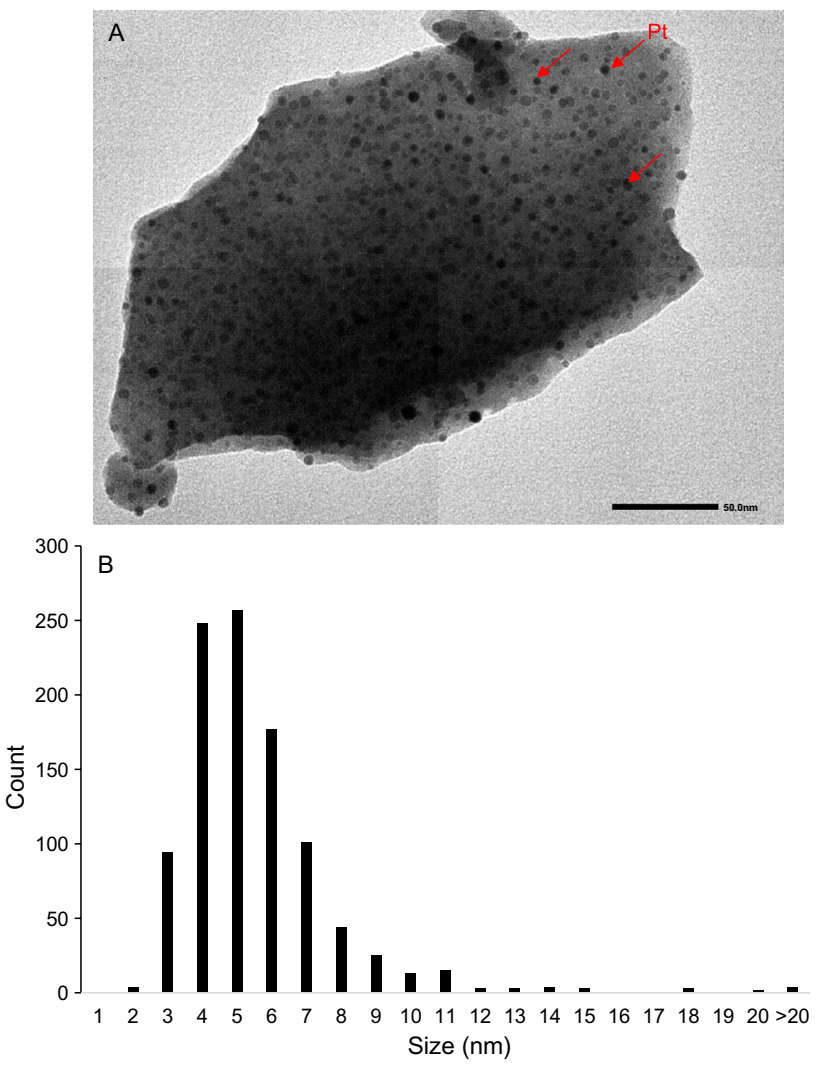

Fig. 8 a TEM image of Cs-P-Pt-800-5 after light irradiation, and b the size distribution of Pt Npts

This reaction mechanism is similar to that of a reported $\mathrm{Pt}$ co-catalyst/EY/K-Al-Si/TiO 2 system [14]. However, since the water-insoluble calcined samples were used without being supported on the surface of titanium oxide, it is possible that the efficiency of electron transfer between titanium oxide and the platinum and/or tungstate sites was reduced. Sintering at high temperatures may also induce three-dimensional microstructural changes and inhibit proton transfer to the platinum sites. In order to overcome these problems, we are investigating methods to support the calcined samples on the surfaces of some semiconducting photocatalytic materials. The results will be reported in due course.

\section{Conclusion}

Two tungstates containing platinum nanoparticles were obtained by air-calcining $\mathrm{Cs}_{3}\left[\alpha-\mathrm{PW}_{11} \mathrm{O}_{39}\left\{\text { cis- } \mathrm{Pt}\left(\mathrm{NH}_{3}\right)_{2}\right\}_{2}\right] \cdot 8 \mathrm{H}_{2} \mathrm{O}$ (Cs-P-Pt) and $\mathrm{Cs}_{4}\left[\alpha-\mathrm{SiW}_{11} \mathrm{O}_{39}\left\{\text { cis- } \mathrm{Pt}\left(\mathrm{NH}_{3}\right)_{2}\right\}_{2}\right] \cdot 11 \mathrm{H}_{2} \mathrm{O}$ (Cs-Si-Pt), at 700-900 ${ }^{\circ} \mathrm{C}$ for $5 \mathrm{~h}$. When Cs-P-Pt was calcined, its $\left\{\mathrm{PW}_{11} \mathrm{O}_{39}\right\}$ unit transformed to $\left\{\mathrm{PW}_{12} \mathrm{O}_{40}\right\}$. In contrast, Cs-Si-Pt exhibited a structural transformation of the $\left\{\mathrm{SiW}_{11} \mathrm{O}_{39}\right\}$ unit to $\left\{\mathrm{W}_{11} \mathrm{O}_{35}\right\}$ under identical calcination conditions. The di-platinum(II) sites in Cs-P-Pt and CsSi-Pt transformed to Pt Npts. The average particle size of Pt Npts generated via air-calcination of Cs-P-Pt was much smaller than that observed when Cs-Si-Pt was calcined. Thus, Cs-P-Pt exhibited an excellent aggregation inhibitory effect at high platinum content and in the absence of a support.

The calcined samples were applied as co-catalysts for hydrogen evolution from aqueous TEOA solutions under visible light irradiation $(\lambda \geq 440 \mathrm{~nm})$ in the presence of Eosin $\mathrm{Y}, \mathrm{K}_{5}\left[\alpha-\mathrm{SiW}_{11}\left\{\mathrm{Al}\left(\mathrm{OH}_{2}\right)\right\} \mathrm{O}_{39}\right] \cdot 7 \mathrm{H}_{2} \mathrm{O}$, and titanium dioxide. Upon calcination at 700-900 ${ }^{\circ} \mathrm{C}$, Cs-P-Pt exhibited higher activities than Cs-Si-Pt. The activity of $\mathbf{C s - P - P t}$ did not diminish after calcination at $800{ }^{\circ} \mathrm{C}$ for $100 \mathrm{~h}$, in comparison with its activity after $5 \mathrm{~h}$ of calcination. It was also confirmed that the Cs-P-Pt sample calcined at $800{ }^{\circ} \mathrm{C}$ for $5 \mathrm{~h}$ exhibited no change in the sizes of the Pt Npts when subjected to light irradiation. Platinum aggregation was thus suppressed under the applied photocatalytic reaction conditions.

Supplementary Information The online version contains supplementary material available at https://doi.org/10.1007/s10562-021-03843-x.

Acknowledgements This work was supported by JSPS KAKENHI Grant Number JP19H02489, and the Research Institute of Green Science and Technology Fund for Research Project Support (2021-RIGST21E03) at National University Corporation, Shizuoka University. We acknowledge Mr. Ryota Kasai (Shizuoka University) for supporting several experiments on the photocatalytic reactions.

\section{Declarations}

Conflict of interest The authors of this work declare that a potential competing interest does not exist. There is not any financial or personal interest or belief that could affect this research work.

Open Access This article is licensed under a Creative Commons Attribution 4.0 International License, which permits use, sharing, adaptation, distribution and reproduction in any medium or format, as long as you give appropriate credit to the original author(s) and the source, provide a link to the Creative Commons licence, and indicate if changes were made. The images or other third party material in this article are included in the article's Creative Commons licence, unless indicated otherwise in a credit line to the material. If material is not included in the article's Creative Commons licence and your intended use is not permitted by statutory regulation or exceeds the permitted use, you will need to obtain permission directly from the copyright holder. To view a copy of this licence, visit http://creativecommons.org/licenses/by/4.0/.

\section{References}

1. R.J.Farrauto and C.H.Bartholomew, Fundamentals of Industrial Catalytic Processes (Blackie Academic \& Professional, 1997)

2. Radivojević D, Seshan K, Lefferts L (2006) Preparation of welldispersed $\mathrm{Pt} / \mathrm{SiO}_{2}$ catalysts using low-temperature treatments. Appl Catal A: Gen 301:51-58 
3. Yati I, Ridwan M, Jeong GE, Lee Y, Choi J, Yoon CW, Suh DJ, Ha J (2014) Effects of sintering-resistance and large metal-support interface of alumina nanorod-stabilized Pt nanoparticle catalysts on the improved high temperature water gas shift reaction activity. Catal Commun 56:11-16

4. Liu B, Xu H, Zhang Z (2012) Platinum based core-shell catalysts for sour water-gas shift reaction. Catal Commun 26:159-163

5. De Rogatis L, Cargnello M, Gombac V, Lorenzut B, Montini T, Fornasiero P (2010) Embedded phases: a way to active and stable catalysts. Chemsuschem 3:24-42

6. M.T. Pope, Heteropoly and isopoly oxometalates (Springer, 1983)

7. Pope MT, Müller A (1991) Chemistry of polyoxometallates. actual variation on an old theme with interdisciplinary references. Angew Chem, Int Ed Engl 30:34-48

8. M.T. Pope and A. Müller, Polyoxometalates: From Platonic Solids to Anti-Retroviral Activity (Springer, 1994)

9. T. Yamase and M.T. Pope, Polyoxometalate Chemistry for NanoComposite Design (Springer, 2002).

10. Sokolov MN, Adonin SA, Peresypkina EV, Fedin VP (2012) A $\mathrm{Pt}(\mathrm{II})$ isopolytungstate: synthesis and crystal structure. Dalton Trans 41:11978-11979

11. Lin Z, Izarova NV, Kondinski A, Xing X, Haider A, Fan L, Vankova N, Heine T, Keita B, Cao J, Hu C, Kortz U (2016) Platinumcontaining polyoxometalates: syn- and anti-[ $\left.\mathrm{Pt}_{2}{ }_{2}\left(\alpha-\mathrm{PW}_{11} \mathrm{O}_{39}\right)_{2}\right]^{10-}$ and formation of the metal-metal-bonded di-Pt ${ }^{\mathrm{III}}$ derivatives. Chem Eur J 22:5514-5519

12. Kato M, Kato CN (2011) A Keggin-type polyoxotungstate-coordinated diplatinum(II) complex: synthesis, characterization, and stability of the cis-platinum(II) moieties in dimethylsulfoxide and water. Inorg Chem Commun 14:982-985

13. Kato CN, Morii Y, Hattori S, Nakayama R, Makino Y, Uno H (2012) Diplatinum(II)-coordinated polyoxotungstate: synthesis, molecular structure, and photocatalytic performance for hydrogen evolution from water under visible-light irradiation. Dalton Trans 41:10021-10027

14. Hattori S, Ihara Y, Kato CN (2015) A novel photocatalytic system constructed using eosin Y, titanium dioxide, and Keggin-type platinum(II)- and aluminum(III)-coordinated polyoxotungstates for hydrogen production from water under visible light irradiation. Catal Lett 145:1703-1709

15. Kato CN, Suzuki S, Ihara Y, Aono K, Yamashita R, Kikuchi K, Okamoto T, Uno H (2016) Hydrogen evolution from water under visible-light irradiation using Keggin-type platinum(II)-coordinated phospho-, silico-, and germanotungstates as co-catalysts. Modern Res Catal 5:103-129

16. Kato CN, Suzuki S, Mizuno T, Ihara Y, Kurihara A, Nagatani $S$ (2019) Syntheses and characterization of $\alpha$-Keggin- and $\alpha_{2}$ Dawson-type diplatinum(II)-coordinated polyoxotungstates: effects of skeletal structure, internal element, and nitrogencontaining ligand coordinated to the platinum center for hydrogen production from water under light irradiation. Catal Today $332: 2-10$
17. Kato CN, Aono K, Kurihara A, Kubota T, Kasai R, Suzuki K (2020) Thermal treatment of a Keggin-type diplatinum(II)-coordinated polyoxotungstate: formation of hydrophilic colloidal particles and photocatalytic hydrogen production. Eur J Inorg Chem 2020:3917-3924

18. Rosenheim A, Jaenicke J (1917) Iso- and heteropolyacids. XV. heteropoly tungstates and some heteropoly molybdates. Z Anorg Allg Chem 101:235-275

19. Tézé A, Hervé G (1990) $\alpha$-, $\beta$-, and $\gamma$-Dodecatungstosilic acids: isomers and related lacunary compounds. Inorg Synth 27:85-96

20. Tézé A, Hervé G (1977) Formation and isomerization of undecaand dodecatungstosilicate and -germanate isomers. J Inorg Nucl Chem 39:999-1002

21. Ivannikova NV, Solodovnikov SF (1995) Refinement of the phase diagram of the $\mathrm{Cs}_{2} \mathrm{WO}_{4}-\mathrm{WO}_{3}$ system. Russ J Inorg Chem 40:1660-1665

22. Narasimharao K, Brown DR, Lee AF, Newman AD, Siril PF, Tavener SJ, Wilson K (2007) Structure-activity relations in Csdoped heteropolyacid catalysts for biodiesel production. J Catal 248:226-234

23. El-Ghannam A, Chandrasekaran S, Sultana F (2021) Synthesis and characterization of a novel nonowire-reinforced $\mathrm{SiC}$ thermal material. J Solid State Chem 297:122055

24. Liu X, Li Y, Peng S, Lu G, Li S (2012) Photocatalytic hydrogen evolution under visible light irradiation by the polyoxometalate $\alpha-\left[\mathrm{AlSiW}_{11}\left(\mathrm{H}_{2} \mathrm{O}\right)_{39}\right]^{5-}$-eosin Y system. Int J Hydrogen Energy 37:12150-12157

25. Liu X, Li Y, Peng S, Lu G (2013) Li S (2013) Photosensitization of $\mathrm{SiW}_{11} \mathrm{O}_{39}{ }^{8-}$-modified $\mathrm{TiO}_{2}$ by eosin $\mathrm{Y}$ for stable visible-light $\mathrm{H}_{2}$ generation. Int J Hydrogen Energy 38:11709-11719

26. Li Y, Xie C, Peng S, Lu G, Li S (2008) Eosin Y-sensitized nitrogen-doped $\mathrm{TiO}_{2}$ for efficient visible light photocatalytic hydrogen evolution. J Mol Catal A Chem 282:117-123

27. Liu X, Li Y, Peng S, Lu G, Li S (2013) Modification of $\mathrm{TiO}_{2}$ with sulfate and phosphate for enhanced eosin Y-sensitized hydrogen evolution under visible light illumination. Photochem Photobiol Sci 12:1903-1910

28. Li Y, Guo M, Peng S, Lu G, Li S (2009) Formation of multilayerEosin Y-sensitized $\mathrm{TiO}_{2}$ via Fe ${ }^{3+}$ coupling for efficient visiblelight photocatalytic hydrogen evolution. Int J Hydrogen Energy 34:5629-5636

29. Dessal C, Martínez L, Maheu C, Len T, Morfin F, Rousset JL, Puzenat E, Afanasiev P, Aouine M, Soler L, Llorca J, Piccolo $\mathrm{L}$ (2019) Influence of Pt particle size and reaction phase on the photocatalytic performances of ultradispersed $\mathrm{Pt} / \mathrm{TiO}_{2}$ catalysts for hydrogen evolution. J Catal 375:155-163

Publisher's Note Springer Nature remains neutral with regard to jurisdictional claims in published maps and institutional affiliations. 